\title{
İş Tatmininin Çalışan Motivasyonu Üzerine Etkileri: Türk İnşaat Sektöründe bir Araştırma
}

\author{
Sarbast MOSLEM ${ }^{1}$, Gözde TANTEKIN ÇELIK ${ }^{* 2}$ \\ ${ }^{1}$ Lincoln Üniversitesi, İnşaat Mühendisliği Bölümü, Mersin \\ ${ }^{2}$ Çukurova Üniversitesi, Mühendislik -Mimarlık Fakültesi, Inşaat Mühendisliği Bölümü, Adana \\ Geliş tarihi: 15.01.2016 Kabul tarihi: 28.03 .2016
}

\section{Özet}

$\mathrm{Bu}$ çalışmada, Türk inşaat sektörü çalışanlarının iş tatminlerinin motivasyonları üzerine etkisinin araştırılması amacıyla mimar, inşaat mühendisi ve teknik elemanlara anket uygulanmıştır. Türk inşaat sektörü çalışanlarının motivasyonunu etkileyen faktörler "yönetim politikası", "kurum içi iletişim", "denetim" ve "yönetici" alt faktörleri olarak belirlenmiştir. Uygulanan korelasyon analizi sonucunda iş tatmini ve motivasyon alt boyutlarının kendi aralarında pozitif ilişki bulunmuş fakat iş tatmini ve motivasyon arasında anlamlı ilişki bulunmamıştır.

Anahtar Kelimeler: Motivasyon, İş tatmini, İnşaat mühendisi, Mimar, Türk inşaat sektörü

\section{Impact of Job Satisfaction on Worker's Motivation: A Research in Turkish Construction Industry}

\begin{abstract}
In this study, a questionnaire survey has been conducted to civil engineers, architects and technical workers, in order to investigate the impact of job satisfaction on motivation of Turkish construction industry professionals. The factors that impact workers motivation in Turkish construction industry are determined to be "management policy", "internal communication", "control" and "manager". As a result of correlation analysis, a positive relationship between the subscales of job satisfaction and motivation was found, but no meaningful relationship was found between job satisfaction and motivation.
\end{abstract}

Keywords: Motivation, Job satisfaction, Civil engineer, Architect, Turkish construction sector

\footnotetext{
* Yazışmaların yapılacağı yazar: Gözde TANTEKİN ÇELIK, Ç.Ü., Mühendislik Mimarlık Fakültesi, Inşsaat Mühendisliği Bölümü, Adana.gtantekin@cu.edu.tr
} 


\section{GíRiș}

İş, çalışanın hayatını devam ettirebilmesi için gereken parayı kazanması amacıyla düzenli olarak gerçekleştirdiği faaliyetler bütünüdür ve çalışanın hayatının büyük bir bölümünü kapsamakta ve psikolojik açıdan etkilenmesine sebep olmaktadır.

Firmalar için çalışanlarının performanslarını optimum seviyeye çıkarmak ve bunu sürdürülebilir kılmak, para, zaman ve kalite üçgeninde ideali yakalayabilmek için en önemli unsurlardan birini oluşturmaktadır. Son yıllarda yapılan çalışmalar, çalışan psikolojisine yönelmiş, iş tatmini ve motivasyon kavramlarının performans ile beraber anılmasına sebep olmuştur [1, 2, 3, 4].

İş tatmini, çalışanların iş ile ilgili yaşadığ 1 olumlu deneyimler sonucunda işini isteyerek yapmasını sağlayan olumlu psikolojik durumu ifade ederken [5], motivasyon ise, güdüleme, isteklendirme kavramıyla açıklanmaktadır. $\mathrm{Bu}$ isteklendirmeyi yaratabilmek için ise kişinin fizyolojik ya da psikolojik bir ihtiyacının karşılanması gerekmektedir. Yapılan araştırmalarda iş tatmini ile motivasyon arasında pozitif ilişki bulunmuştur [6]. Bu doğrultuda iş tatminini sağlayan unsurların bilinmesi, yöneticilere ipuçları vermekte ve isabetli motivasyon stratejileri geliştirmelerini olanak sağlamaktadır. Bu çalışmanın amacı, Türk inşaat sektörü çalışanlarının motivasyon faktörlerini belirlemek, iş tatmini ve motivasyon arasındaki ilişkiyi sorgulayarak firmalara önerilerde bulunmaktır.

\section{MATERYAL VE METOT 2.1. Materyal}

Çalışmanın örneklemini Türkiye genelinde çalışan mimar, inşaat mühendisi ve teknik elemanlar oluşturmaktadır. Veri toplamak amaciyla www.google.com.form sitesinde online anket oluşturulmuş ve Nisan 2015 tarihinde YEM (Yapı Endüstri Merkezi) aracılığı ile 20.000 kişiye ulaştırılmıştır. Çalışmanın sonucunda 332 anket değerlendirmeye uygun bulunmuştur.

\subsection{Metot}

Çalışmanın temelini oluşturan iş tatmini ve motivasyonu ölçmek amaciyla 3 bölümden oluşan bir anket hazırlanmıştır. Birinci bölüm demografik özellikler, ikinci bölüm iş tatmini ve üçüncü bölüm de motivasyon sorularından oluşmaktadır.

Anketin birinci bölümünde çalışanların meslek, cinsiyet, yaş, medeni durum, eğitim, gelir ve mesleki deneyim gibi demografik özellikleri ile ilgili veri toplanması hedeflenmiştir. İkinci bölümde, Weiss ve arkadaşlarının [7] iş tatminini ölçmek amacıyla oluşturdukları, iç tatmin, dış tatmin ve genel tatmin (her iki boyutu da kapsamaktadır) alt boyutlarından oluşan Minnesota İş Tatmini Anketi'nin (Minnesota Satisfaction Questionnaire) 20 soruluk kısa hali kullanılmıştır. Minnesota İş Tatmini Anketi'ne ait soruların boyutlar altındaki dağılımı Çizelge 1'de verilmiştir.

Çizelge 1. Çalışmada kullanılan Minnesota iş tatmini anketi ve boyutları tanımlayan soru grupları

\begin{tabular}{|c|c|}
\hline \multicolumn{2}{|c|}{ İş Tatmini Soru Grupları } \\
\hline Boyut & Soru Numarası \\
\hline İç Tatmin & $1,2,3,4,7,8,9,10,11,15,16,20$ \\
\hline Diş Tatmin & $5,6,12,13,14,17,18,19$ \\
\hline Genel Tatmin & $1-20$ Soruların Bütünü \\
\hline
\end{tabular}

Araştırmanın üçüncü bölümünde çalışanların motivasyonunu ölçmek amaciyla temeli İncir'in [8] oluşturduğu iş tatmini anketine dayanan,
Öztürk ve Dündar'ın [9] geliştirdikleri 30 soruluk motivasyon anketi kullanılmıştır. Çalışmanın temelini oluşturan iş tatmini ve motivasyon 
soruları 5'li Likert tipi ölçeğe göre cevaplandırılacak şekilde oluşturulmuştur. Ankete katılanların boyut puanları hesaplanırken verdikleri cevaplara ait puanlar toplanmış ve soru sayısına bölünerek her bir boyuta ait ortalama değerler bulunmuştur. Böylece iş tatmini ve motivasyon ölçeklerinin her bir boyutunun altında bulunan soru sayısı farklı olmasına rağmen tüm boyut puanları standardize edilerek 1-5 arasında ifade edilmiştir.

Anketin değerlendirilmesinde kullanılan puan aralıkları ve değerlendirme kriterleri Çizelge 2'de verilmiştir [10].

Çizelge 2. Anketlerin değerlendirilmesinde kullanılan puan aralıkları

\begin{tabular}{|c|c|c|c|c|}
\hline \multirow{2}{*}{$\begin{array}{l}\text { Likert } \\
\text { Ölçeği }\end{array}$} & \multicolumn{2}{|c|}{ Anketler } & \multirow{2}{*}{$\begin{array}{c}\text { Puan } \\
\text { Aralıkları }\end{array}$} & \multirow{2}{*}{$\begin{array}{l}\text { Değerlendirme } \\
\text { Kriterleri }\end{array}$} \\
\hline & Motivasyon & İş Tatmini & & \\
\hline 1 & Hiç katılmıyorum & Beni Hiç Tatmin Etmiyor & $1,00-1,79$ & Çok az düzeyde \\
\hline 2 & Katılmiyorum & Beni Pek Tatmin Etmiyor & $1,80-2,59$ & Az düzeyde \\
\hline 3 & Kararsızım & Kararsızım & $2,60-3,39$ & Orta düzeyde \\
\hline 4 & Katıliyorum & $\begin{array}{l}\text { Beni Oldukça Tatmin } \\
\text { Ediyor }\end{array}$ & $3,40-4,19$ & Yüksek düzeyde \\
\hline 5 & $\begin{array}{c}\text { Tamamen } \\
\text { katıliyorum }\end{array}$ & $\begin{array}{l}\text { Beni Tamamiyla Tatmin } \\
\text { Ediyor }\end{array}$ & $4,20-5,00$ & $\begin{array}{l}\text { Çok yüksek } \\
\text { düzeyde }\end{array}$ \\
\hline
\end{tabular}

Çalışma kapsamında ölçeklerin güvenilirliği Cronbach Alpha $(\alpha)$ katsayıları hesaplanarak, veri setinin normal dağılıma uygunluğu ise Kolmogrov-Smirnov testine bakılarak incelenmiştir. Motivasyon ölçeğine açımlayıcı faktör analizi uygulanmış ve motivasyon ölçeği alt boyutları isimlendirilmişsir. Örneklemin iş tatmini ve motivasyon alt boyutlarına ait ortalamaları hesaplanmış ve değerlendirme kriterlerine göre yorumlanmıştır. İş tatmini ve motivasyon arasındaki ilişkiler ise Spearman-korelasyon testi kullanılarak incelenmiştir.

Analizler için Microsoft Office Excel 2007 ve SPSS 18 (The Statistical Packet for The Social
Sciences) paket programları kullanılmıștır. Veri toplamak amaciyla hazırlanan anket 159 mimar, 157 inşaat mühendisi ve 16 teknik elemana uygulanmış ve toplanan veriler istatistiksel olarak değerlendirilmiştir.

\section{BULGULAR}

İş tatmini ve motivasyon anketi için hesaplanan Cronbach Alpha değerleri Çizelge 3'de verilmiştir. Cronbach Alpha değerlerinin 0.6'dan büyük olması, anketlerin "oldukça güvenilir" olduğunu göstermektedir.

Çizelge 3. Kullanılan anketlerin güvenilirlikleri

\begin{tabular}{|c|c|}
\hline Anket & Cronbach Alpha Katsayısı \\
\hline Motivasyon & 0,861 \\
\hline İş Tatmini & 0,948 \\
\hline
\end{tabular}

Çalışma sonucunda toplanan verilere KolmogrovSmirnov Testi uygulanmış ve verilerin normal dağılıma uymadığg 1 görülmüştür.
Türk inşaat sektörü çalışanlarının motivasyonlarını ölçmek amacıyla kullanılan 30 sorudan oluşan ölçeğe Temel Bileşenler Analizi (Principal 
Component Analysis-PCA) yönetimi ile açımlayıcı faktör analizi uygulanmıştır. Yapılan analiz sonucunda; 13. Soru anti-image korelasyon matrisindeki değeri 0,5'ten küçük olduğu için [10]; $4,10,11,14$, ve 15 . Sorular ise ortak varyans tablosundaki değerleri 0,32 'den küçük olduğu için elenmiştir. Kalan 24 soru için Varimax döndürme yöntemi kullanılmış ve motivasyon ölçeğine ait sorular 4 faktör altında toplanmıştır. Faktör yükleri birinci faktör için 0,785-0,575 arasında; ikinci faktör için 0,713-0,476 arasında; üçüncü faktör için 0,803-0,559 arasında ve dördüncü faktör için ise $0,663-0,651$ arasında değişmektedir. Faktörlerin toplam varyansa yaptıkları katkının, birinci faktör için \%23,278, ikinci faktör için $\% 14,337$, üçüncü faktör için $\% 8,771$ ve dördüncü faktör için $\% 7,836$ olduğu görülmüştür. Belirlenen dört faktörün varyansa yaptıkları toplam katkı \%54,222'dir. Motivasyon ölçeğine yapılan açımlayıcı faktör analizi sonucunda birinci faktör adaletli terfi imkanları; adaletli ücret dağılımı, takdir edilme, ödüller gibi unsurlar içermekte olduğu için "yönetim politikası" olarak; ikinci faktör kurum içi insan ilişkilerini ve şeffaf iletişim gibi unsurları içerdiği için "kurum içi iletişim" olarak; üçüncü faktör kurum içi denetim ile ilgili unsurları içerdiği için "denetim" olarak; dördüncü faktör ise yöneticinin yönetici vasfi ve astlara olan davranışı ile ilgili olduğu için "yönetici" olarak isimlendirilmiştir (Çizelge 4).

Çizelge 4. Motivasyon ölçeğinin faktör deseni

\begin{tabular}{|l|c|c|c|c|}
\hline \multirow{2}{*}{ Anket Soruları } & \multicolumn{3}{|c|}{ Motivasyon Sorularının Faktör Yükleri } \\
\cline { 2 - 5 } & $\begin{array}{c}\text { Yönetim } \\
\text { politikası }\end{array}$ & Kurum içi iletişim & Denetim & Yönetici \\
\hline $\mathbf{2 0}$ & 0,785 & 0,269 & 0,055 & $-0,089$ \\
\hline $\mathbf{1 9}$ & 0,764 & 0,199 & $-0,038$ & $-0,148$ \\
\hline $\mathbf{1 7}$ & 0,712 & 0,116 & 0,044 & $-0,026$ \\
\hline $\mathbf{2 1}$ & 0,640 & 0,403 & 0,095 & $-0,091$ \\
\hline $\mathbf{2 2}$ & 0,678 & 0,414 & 0,034 & $-0,052$ \\
\hline $\mathbf{1 6}$ & 0,655 & 0,244 & $-0,111$ & $-0,030$ \\
\hline $\mathbf{2 3}$ & 0,640 & 0,428 & 0,129 & $-0,085$ \\
\hline $\mathbf{1 2}$ & 0,625 & 0,187 & 0,002 & $-0,066$ \\
\hline $\mathbf{2 5}$ & 0,600 & 0,578 & 0,048 & $-0,091$ \\
\hline $\mathbf{7}$ & 0,580 & 0,110 & $-0,055$ & 0,176 \\
\hline $\mathbf{1 8}$ & 0,575 & 0,006 & $-0,197$ & 0,206 \\
\hline $\mathbf{2 6}$ & 0,326 & 0,713 & $-0,128$ & $-0,009$ \\
\hline $\mathbf{2 4}$ & 0,111 & 0,691 & $-0,214$ & 0,067 \\
\hline $\mathbf{2 7}$ & 0,199 & 0,672 & 0,029 & 0,070 \\
\hline $\mathbf{2 9}$ & 0,207 & 0,605 & 0,126 & $-0,016$ \\
\hline $\mathbf{2 8}$ & 0,504 & 0,547 & 0,109 & 0,019 \\
\hline $\mathbf{3 0}$ & 0,381 & 0,476 & $-0,033$ & $-0,220$ \\
\hline $\mathbf{2}$ & $-0,008$ & $-0,074$ & 0,803 & 0,150 \\
\hline $\mathbf{3}$ & 0,118 & 0,071 & 0,673 & 0,050 \\
\hline $\mathbf{5}$ & $0-, 074$ & 0,012 & 0,607 & 0,426 \\
\hline $\mathbf{8}$ & $-0,237$ & $-0,095$ & 0,559 & $-0,425$ \\
\hline $\mathbf{9}$ & $-0,031$ & 0,002 & 0,061 & 0,663 \\
\hline $\mathbf{6}$ & $-0,070$ & 0,022 & $-0,007$ & 0,660 \\
\hline $\mathbf{1}$ & 0,004 & $-0,085$ & 0,376 & 0,651 \\
\hline & KMO & Bartlett Küresellik Testi sig. $=0,000$ & \\
\hline & & & \\
\hline
\end{tabular}


Çizelge 5'te inşaat sektörü çalışanlarının motivasyon sonuçları verilmiştir. Türk inşaat sektörü çalışanlarının motivasyonlarını etkileyen faktörler incelendiğinde yönetim politikaları $(\bar{x}=4,41)$ ve kurum içi iletişim faktörü $(\bar{x}=4.23)$ “çok yüksek" düzeyde $(4,19<\overline{\mathrm{x}}<5.00)$; denetim faktörünün $(\overline{\mathrm{x}}=3,09)$ "orta" düzeyde $(2,59<\overline{\mathrm{x}}<$ $3,40)$ ve yönetici faktörünün $(\bar{x}=2.21)$ "az" düzeyde $\quad(1,79<\overline{\mathrm{x}}<2,60) \quad$ etkili olduğu görülmektedir. Çalışanlar mesleklerine göre incelendiğinde ise etkili olan faktörlerin sıralamasının değişmediği ve adaletli terfi imkanları, iş bölümü, ücret, takdir edilme gibi etkenleri kapsayan yönetim politikaları faktörü ile ast-üst ilişkileri, firma içi sosyal ortam gibi etkenleri kapsayan kurum içi iletişim faktörünün öne çıktığı görülmektedir. Türk inşaat sektörü çalışanları için denetim de önemli olmakla birlikte yönetici faktörünün çok etkili olmadığı görülmüştür (Çizelge 5).

Çizelge 5. İnşaat sektörü çalışanlarının motivasyon sonuçları

\begin{tabular}{|c|c|c|c|c|c|c|c|c|}
\hline \multirow{2}{*}{ Cevap Sayısı } & \multicolumn{2}{c|}{$\begin{array}{c}\text { Tüm } \\
\text { Örneklem }\end{array}$} & \multicolumn{2}{c|}{$\begin{array}{c}\text { İnşaat } \\
\text { Mühendisi }\end{array}$} & \multicolumn{2}{|c|}{ Mimar } & \multicolumn{2}{c|}{$\begin{array}{c}\text { Diğer } \\
\text { (teknik elaman) }\end{array}$} \\
\cline { 2 - 10 } & \multicolumn{2}{|c|}{$\mathbf{3 3 2}$} & \multicolumn{2}{|c|}{$\mathbf{1 5 7}$} & \multicolumn{2}{|c|}{$\mathbf{1 5 9}$} & \multicolumn{2}{|c|}{$\mathbf{1 6}$} \\
\hline Motivasyon & $\overline{\mathbf{x}}$ & $\boldsymbol{\sigma}$ & $\overline{\mathbf{x}}$ & $\boldsymbol{\sigma}$ & $\overline{\mathbf{x}}$ & $\boldsymbol{\sigma}$ & $\overline{\mathbf{x}}$ & $\boldsymbol{\sigma}$ \\
\hline Yönetim Politikaları & 4,41 & 0,50 & 4,37 & 0,52 & 4,45 & 0,48 & 4,38 & 0,48 \\
\hline Kurum İçi İletişim & 4,23 & 0,58 & 4,18 & 0,61 & 4,27 & 0,55 & 4,26 & 0,61 \\
\hline Denetim & 3,09 & 0,66 & 3,03 & 0,67 & 3,16 & 0,65 & 3,02 & 0,73 \\
\hline Yönetici & 2,21 & 0,87 & 2,17 & 0,86 & 2,22 & 0,88 & 2,34 & 0,95 \\
\hline
\end{tabular}

Çizelge 6'da inşaat sektörü çalışanlarının iş tatmini sonuçları verilmiştir. Türk inşaat sektörü çalışanlarının iç $(\bar{x}=3,26)$, dış $(\bar{x}=3,03)$ ve genel tatminlerinin $(\overline{\mathrm{x}}=3,17)$ "orta" düzeyde $(2,59<\overline{\mathrm{x}}<3,40)$ olduğu görülmektedir. Çalışanlar mesleklerine göre incelendiğinde ise teknik elemanların, mimar ve inşaat mühendislerine göre iş tatminlerinin daha yüksek olduğu, inşaat mühendislerinin ise en düşük tatmine sahip olan grup olduğu görülmektedir (Çizelge 6).

Çizelge 6. İnşaat sektörü çalışanlarının iş tatmini sonuçları

\begin{tabular}{|c|c|c|c|c|c|c|c|c|}
\hline \multirow{2}{*}{ Cevap Sayısı } & \multicolumn{2}{|c|}{$\begin{array}{c}\text { Tüm } \\
\text { Örneklem }\end{array}$} & \multicolumn{2}{c|}{$\begin{array}{c}\text { İnşaat } \\
\text { Mühendisi }\end{array}$} & \multicolumn{2}{c|}{ Mimar } & \multicolumn{2}{c|}{$\begin{array}{c}\text { Diğer(teknik } \\
\text { elaman) }\end{array}$} \\
\cline { 2 - 11 } & \multicolumn{2}{|c|}{$\mathbf{3 3 2}$} & \multicolumn{2}{|c|}{$\mathbf{1 5 7}$} & \multicolumn{2}{|c|}{$\mathbf{1 5 9}$} & \multicolumn{2}{c|}{$\mathbf{1 6}$} \\
\hline İş Tatmini & $\overline{\mathbf{x}}$ & $\sigma$ & $\overline{\mathbf{x}}$ & $\sigma$ & $\overline{\mathbf{x}}$ & $\sigma$ & $\overline{\mathbf{x}}$ & $\sigma$ \\
\hline İç Tatmin & 3,26 & 0,92 & 3,23 & 0,93 & 3,26 & 0,92 & 3,67 & 0,74 \\
\hline Dış Tatmin & 3,03 & 0,92 & 2,95 & 0,98 & 3,06 & 0,87 & 3,48 & 0,82 \\
\hline Genel Tatmin & 3,17 & 0,89 & 3,11 & 0,92 & 3,18 & 0,86 & 3,59 & 0,74 \\
\hline
\end{tabular}

İnşaat sektörü çalışanlarının motivasyon ve iş tatminleri arasındaki ilişkilerin incelenmesi amaciyla Spearman Korelasyon Testi uygulanmış ve sonuçlar aşağıda özetlenmiştir (Çizelge 7). 
Çizelge 7. Motivasyon ve iş tatmini alt boyutları arasındaki korelasyon değerleri

\begin{tabular}{|l|l|l|l|l|l|l|l|}
\hline Değişkenler & \multicolumn{1}{|c|}{$\mathbf{1}$} & \multicolumn{1}{|c|}{$\mathbf{2}$} & $\mathbf{3}$ & $\mathbf{4}$ & $\mathbf{5}$ & $\mathbf{6}$ & $\mathbf{7}$ \\
\hline 1- Yönetim politikası & 1 & & & & & & \\
\hline 2- Kurum içi iletişim & $0,612^{* *}$ & 1 & & & & & \\
\hline 3-Denetim & $-0,145^{* *}$ & $-0,142^{* *}$ & 1 & & & & \\
\hline 4- Yönetici & $-0,191^{* *}$ & $-0,182^{* *}$ & $0,240^{* *}$ & 1 & & & \\
\hline 5- İç Tatmin & 0,028 & $-0,044$ & 0,008 & 0,018 & 1 & & \\
\hline 6- Dış Tatmin & $-0,030$ & $-0,095$ & $-0,016$ & $-0,015$ & $0,839^{* *}$ & 1 & \\
\hline 7- Genel Tatmin & 0,008 & $-0,069$ & $-0,002$ & 0,008 & $0,973^{* *}$ & $0,938^{* *}$ & 1 \\
\hline
\end{tabular}

** Korelasyon 0.01 düzeyinde anlamlıdır (2 kuyruklu)

Çizelge 7 'teki sonuçlar incelendiğinde motivasyon ve iş tatmini arasında anlamlı ilişki bulunmazken, motivasyon alt boyutları incelendiğinde "yönetim politikası" ve "kurum içi iletişim" alt boyutları arasinda orta düzeyde pozitif; "denetim" ve "yönetici" alt boyutları arasında ise çok düşük pozitif iliş̧ki bulunmuştur. İş tatmini alt boyutları incelendiğinde "iç tatmin" ve "dış tatmin" boyutları arasında yüksek pozitif; "genel tatmin" ile "iç tatmin" ve "dış tatmin" arasında ise çok yüksek pozitif ilişki olduğu görülmektedir.

\section{TARTIŞMA VE SONUÇLAR}

Anket çalışmasına 159 mimar, 157 inşaat mühendisi ve 16 teknik eleman olmak üzere toplam 332 kişi katılmıştı. Türk inşaat sektörü çalışanlarının motivasyonlarını ölçmek amacıyla kullanılan ankete açımlayıcı faktör analizi uygulanmış ve motivasyon "yönetim politikası", "kurum içi iletişim", "denetim" ve "yönetici" alt boyutları olarak isimlendiren dört faktör altında toplanmıştır. Kuruoğlu ve Polat [11] ise inşaat sektörü çalışanlarını motive eden faktörleri gayri maddi, maddi ve sosyal faktörler olmak üzere üç gruba ayırmışlardır.

Motivasyon anketine ait ortalama sonuçları incelendiğinde adaletli terfi imkanları, adaletli ücret dağılımı, takdir edilme ve ödüller gibi unsurları içeren "yönetim politikaları" ve kurum içi insan ilişkilerini içeren "kurum içi iletişim" faktörlerinin inşaat sektörü çalışanları için motivasyon faktörleri olarak ön plana çıktığı görülmüştür [12].

Türk inşaat sektörü çalışanlarının tüm tatmin boyutlarının "orta" düzeyde olduğu görülmüştür. Varışlı 2010'da yaptığı çalışmada inşaat sektörü çalışanlarının iş tatmini düzeylerini "yüksek" bulmuş̧ur [13]. Çelik [10] de inşaat sektörü çalışanların iç tatmin boyutunu "yüksek", dış ve genel tatmin boyutunu ise "orta" düzeyde bulmuştur. $\mathrm{Bu}$ çalışma sonucunda son yıllarda inşaat sektörü çalışanlarının tatmin düzeylerinde azalma olduğu görülmektedir.

Yapılan korelasyon analizinde "yönetim politikası" ve "kurum içi iletişim" arasında pozitif ve "denetim" ile "yönetici" alt boyutları arasında da pozitif ilişki bulunmuştur. İş tatmini alt boyutlarının da birbiriyle aralarında "yüksek" pozitif ilişki bulunmuştur [10].

Son yıllarda yapılan çalışmaların genelinde iş tatmini ve motivasyon arasında pozitif ilişsi bulunmuştur $[6,14]$. Bu çalışmada ise literatürün aksine Türk inşaat sektörü çalışanlarının iş tatmini ve motivasyonları arasında anlamlı ilişki bulunamamıştır. Bu çalışmaya paralel olarak Pekel [15] de Antalya havaalanı çalışanları arasında yaptığı çalışmada iş tatmini ve motivasyon arasında ilişki bulamamıştır.

\section{5. ÖNERILER}

Çalışma sonucunda literatür bulgularının aksine iş tatmini ve motivasyon arasında ilişki 
bulunmamıştır. $\mathrm{Bu}$ sonuç doğrultusunda iş tatmininin motivasyonu direkt etkilemek yerine çalışanın motive edilmesini kolaylaştıran bir psikolojik durum olduğu söylenebilir. $\mathrm{Bu}$ çalışmanın sonucunun genel literatür bulgularından farklı çıkması sebebiyle benzer hedef kitlenin genişletilerek farklı iş tatmini ve motivasyon ölçekleri kullanılması ve/veya farklı değişkenler de eklenerek çalışmanın tekrar edilmesi önerilmektedir.

Çalışma sonucunda elde edilen genel bulgular doğrultusunda yöneticilere aşağıdaki öneriler sunulmuştur.

(1) Türk inşaat sektörü çalışanları için adaletli iş bölümü, adaletli terfi politikası gibi yönetim politikalarının motivasyonu sağlamada önemli olduğu ve yöneticilerin kurum içi “adalet" algısına dikkat etmesi gerektiği görülmüştür.

(2) Kurum içi iletişim çalışanlar için önemlidir ve firma içi yapılacak sosyal aktiviteler, çalışanların sosyal ihtiyaçlarını gidermelerine imkan sağlayabilir.

(3) Türk inşaat sektörü çalışanlarının iş tatminleri orta seviye çıkmıştır. Firma içinde çalışanların iyi gözlenmesi ve ihtiyaç düzeylerine göre belirlenen motivasyon araçlarının zamanında, yeterli miktarda, uygun ve adaletli bir şekilde uygulanması ile çalışanların iş tatmin düzeyleri yükseltilmeli ve bu bir seferlik bir strateji olarak değil yönetim tarzı olarak benimsenmeli ve yakalanan olumlu psikolojik durum sürdürülebilir k1lınmalıdır.

\section{TEŞEKKÜRLER}

Çalışmalarımıza maddi destek veren Ç.Ü. Bilimsel Araştırma Projeleri Birimine (BAP), (Proje No: 3709) içten teşekkürlerimizi sunarı.

Araştırmalarımıza katkılarından dolayı Yapı Endüstri Merkezi'ne (YEM) ve Yurtdışı Türkler ve Akraba Topluluğu Başkanlığı'na (YTB) teşekkürlerimizi sunarız.

\section{KAYNAKLAR}

1. Özmutaf, N., M., 2007. Örgütlerde Bireysel Performans Unsurları ve Çatışma, Ç. Ü. İktisadi ve İdari Bilimler Dergisi, Cilt 8, Say1:2, 41-60.

2. Tümgan, C., 2007. Kamu Örgütlerinde Motivasyon ve İş Tatmini, Kahramanmaraş Sütçü İmam Üniversitesi, Sosyal Bilimler Enstitüsü, Yüksek Lisans Projesi, Kahramanmaraş, 46s.

3. Ertan, H., 2008. Örgütsel Bağll1ık, İş Motivasyonu ve İş Performansı Arasındaki İlişki: Antalya'da Beş Yıldızlı Otel İşletmelerinde Bir İnceleme, Afyon Kocatepe Üniversitesi, Sosyal Bilimler Enstitüsü, Doktora Tezi, Afyon, 192s.

4. Leung, M.Y., Chong, A., Cheung, M.C.K., 2004. Demystifying Stakeholders Commitment and It's Impact on Construction Projects, Construction Management and Economics, 22:7, 701-715.

5. Türk, M. S., 2003. Bir İletişim Sistemi Olan Örgüt Kültürünün İş Tatmini Üzerindeki Etkisi ve Önemi, Selçuk Üniversitesi, Sosyal Bilimler Enstitüsü, Doktora Tezi, Konya.

6. Büyükdemirusta, H., 2007. Kamuda Çalışanların Motivasyonunu Etkileyen Unsurlar: Saü, Sedas ve Sakarya İl Emniyet Müdürlüğü Örneği, SakaryaÜniversitesi, Sosyal Bilimler Enstitüsü, Kamu Yönetimi Anabilim Dalı, Sakarya.

7. Weiss, D.J., Davis, R.V., England, G.W., Lofguist, L.H., 1967. Manual for the Minnesota Satisfaction Questionnaire, Minnesota Studies Vocational Rehabilitations: xxii, Department of Health, Education and Welfare, Washington, 119s.

8. İncir, G., 1990. Çalışanların İş Tatmini Üzerine Bir İnceleme, Verimlilik Dergisi, No:401, Ankara.

9. Öztürk, Z., Dündar, H., 2003. Örgütsel Motivasyon ce Kamu Çalışanlarını Motive Eden Faktörler, C.Ü. İktisadi ve İdari Bilimler Dergisi, Cilt 4, Sayı 2. 
10. Çelik, G., 2013. Türk İnşaat Sektörü Çalışanlarının Kişilik Özeliklerinin, Örgütsel Bağlılık ve İş Tatmini Etkisi. Doktora Tezi, Çukurova Üniversitesi, Fen Bilimler Enstitüsü, Adana, 338s.

11. Kuruoğlu, M., Polat, G., 2002. İnşaat Sektöründe Çalışan Promosyonları Motive Eden Faktörler, TMH - Türkiye Mühendislik Haberleri Sayı 417 2002/1.

12. Moslem, S., 2015. İş Tatmininin Çalışan Motivasyonu Üzerine Etkileri: Türk İnşaat Sektöründe Bir Araştırma. Yüksek Lisans Tezi, Çukurova Üniversitesi, Fen Bilimleri Enstitüsü, Adana, 77s.

13. Varışlı, Y., 2010. İnşaat Firmalarında Çalışanların İş Tatmini, Çukurova Üniversitesi, Fen Bilimler Enstitüsü, Yüksek Lisans Tezi, Adana,70s.

14. Çankaya, İ.H., Töremen, F., Şanlı, Ö., 2011. Okul Güvenliğinin İlköğretim Okulu Öğretmenlerinin Kayg1, Motivasyon ve İş Doyumu Düzeyleri Üzerindeki Etkisi, Gümüşhane Üniversitesi, Sosyal Bilimler Elektronik Dergisi, Sayı 3, 80-98s.

15. Pekel, H., N., 2001. İşletmelerde Motivasyon Verimlilik İlişkisi Devlet Hava Meydanları İşletmesi Antalya Havalimanı Çalışanları Arasında Bir Örnek Olay Araştırması. Süleyman Demirel Üniversitesi Sosyal Bilimler Enstitüsü, Yüksek Lisans Tezi, Isparta, 219s. 